\begin{tabular}{|c|l|}
\hline Title & Microstructure formation during the annealing of iron nitrides \\
\hline Author(s) & Saito, R.; Masubuchi, Y.; Motohashi, T.; Kikkawa, S.; Sasaki, M. \\
\hline Citation & $\begin{array}{l}\text { Materials Research Bulletin, 46/4), 547-550 } \\
\text { https://doi.org/40.1016/.materresbull.2010.12.032 }\end{array}$ \\
\hline Issue Date & 2011-04 \\
\hline Doc URL & http://hdl.handle.net/2115/45260 \\
\hline Type & article (author version) \\
\hline File Information & MRB46-4_547-550.pdf \\
\hline
\end{tabular}

Instructions for use 


\title{
Microstructure formation during the annealing of iron nitrides
}

\author{
R. Saito ${ }^{1}$, Y. Masubuchi ${ }^{1}$, T. Motohashi ${ }^{1}$, S. Kikkawa ${ }^{1 *}$ and M. Sasaki ${ }^{2}$ \\ ${ }^{1}$ Graduate School of Engineering, Hokkaido University \\ N13W8, Kita-ku, Sapporo 060-8628, Japan
${ }^{2}$ National Institute of Advanced Industrial Science and Technology Hokkaido 2-17-2-1, Tsukisamu-Higashi, Toyohira-ku, Sapporo 062-8517, Japan

\begin{abstract}
The thermal metastability of iron nitride was exploited to fabricate thin-film microstructures applicable to left-handed metamaterials. A granular thin film containing dispersed iron particles was prepared by post-annealing an rf-sputter-deposited $\mathrm{Fe}_{0.5} \mathrm{Al}_{0.5} \mathrm{~N}$ thin film with a wurtzite-type structure in a nitrogen atmosphere at $450^{\circ} \mathrm{C}$. The obtained samples showed magnetic resonance in the microwave region. Laser direct writing was also applied in a nitrogen atmosphere to an rf-sputter-deposited $\mathrm{Fe}_{0.7} \mathrm{Al}_{0.3} \mathrm{~N}$ thin film. $200 \mu$ m-wide, $300 \Omega \mathrm{cm}$ iron metal lines were drawn in a host nitride film of approximately $2 \mathrm{k} \Omega \mathrm{cm}$. Combining and optimizing the above negative permeability and permittivity values should provide left-handed materials with a negative refractive index.
\end{abstract}

${ }^{*}$ Corresponding author, Fax: +81-(0)11-706-6739

E-mail address: kikkawa@eng.hokudai.ac.jp 


\section{Introduction}

Micro-patterning is a very important step in the fabrication of microdevices. Photolithography is the most common and well-established technique of micro-patterning, and has been widely used to draw microcircuits on semiconductors. The technique includes several steps, such as resist coating, light exposure, development, etching, and resist removal. Micro-patterning has attained a resolution of several tens of nanometers under UV light exposure, although it is difficult to obtain a higher resolution than the wavelength of the exposing light [1]. Thermal patterning is a much simpler procedure than photolithography, and has reached a similar resolution (below $100 \mathrm{~nm}$ ) using laser direct writing [2]. A high sensitivity to temperature is required to attain high resolution in the resist materials.

Because they can have a negative refractive index, left-handed metamaterials have attracted considerable attention for new applications such as superlenses and invisibility cloaks [3, 4]. They may also enable patterning at a higher resolution than the wavelength of the exposing light. Negative values of both permittivity and permeability are simultaneously required to attain this negative refractive index. Most of the research to date has been performed on combinations of split-ring metallic resonators and metal wires of millimeter size operating in the terahertz range $[5,6]$. Both the resonators and 
the wires size should be smaller to operate at higher frequencies, and micro-patterning may help enable this miniaturization. Magnetic resonance was proposed as an another possible candidate for the split-ring resonator [7] and was realized in a composite polyimide film containing dispersed superparamagnetic Ni nanoparticles prepared by thermal reduction of adsorbed $\mathrm{Ni}^{2+}$ ions from an aqueous solution in the film [8].

Some nitrides of 3d-transition metals thermally decompose at several hundred degrees Celsius. This metastability has been attributed to anti-bonding characteristics of their chemical bonding [9]. This behavior has been applied to fabricate magnetoresistive Fe-AlN and $\mathrm{Fe}_{0.7} \mathrm{Co}_{0.3}$-AlN granular thin films by post-annealing rf-sputter-deposited solid solution films between AlN and either FeN or FeCoN [10, 11]. Ferromagnetic metal particles approximately $30 \mathrm{~nm}$ in diameter were embedded in an insulating matrix by optimizing the as-sputtered film composition and annealing conditions.

In the present study, the thermal annealing of rf-sputter-deposited Fe-Al nitride thin films was investigated for the fabrication of composite films containing dispersed Fe nanoparticles. Laser direct writing on an Fe-Al solid solution nitride film was also investigated for the drawing of Fe metal lines of micrometer width in the matrix. 


\section{Experimental}

A composite target of $\mathrm{Al}$ chips $\left(1 \times 1 \mathrm{~cm}^{2}, 99.97 \%\right.$, Furuuchi Chemical Co.) distributed on an Fe disk (3 inch $\phi, 99.97 \%$, Furuuchi Chemical Co.) was sputtered using rf-magnetron sputtering equipment (JEOL, JEC-SP360M). The sputtering gas was $\mathrm{N}_{2}$ of $6 \mathrm{~N}$ purity, and the pressure was maintained at $5.5 \mathrm{~Pa}$ during the deposition. Films were deposited on silica glass substrates under an applied rf power of $100 \mathrm{~W}$. The Fe content was varied by changing the $\mathrm{Al} / \mathrm{Fe}$ area ratio of the sputtering target. The target-to-substrate distance was $35 \mathrm{~mm}$. The as-deposited films for 2 hrs were annealed for $1 \mathrm{hr}$ in a nitrogen flow to obtain granular films. The annealing temperature was varied from 450 to $600^{\circ} \mathrm{C}$.

Laser direct writing was applied to the above as-deposited Fe-Al nitride films and FeN film, in an ambient, vacuum, or nitrogen atmosphere. A laser beam with a wavelength of $809 \mathrm{~nm}$ was generated by a semiconducting laser (BEF-2, B \& W TEK Co.) and irradiated on the films, which were placed on a computer-controlled XYZ stage (TT, IAI Co.). The laser beam was focused to a spot size of approximately 1.5-2.0 mm using convex lenses with focal lengths of 3 or $6 \mathrm{~cm}$ (SLB-30-35P, SLB-30-60P, Sigma Koki Co.), and then scanned at $1.0 \mathrm{~mm} / \mathrm{s}$.

The film texture and chemical composition were analyzed using scanning electron 
microscopy combined with energy dispersive X-ray spectroscopy (SEM-EDS; JED-2300, JEOL) following optical microscopic observations (SMZ-10A, Nikon).

The crystal structure was studied by X-ray diffractometry (XRD) using monochromatic $\mathrm{Cu}-\mathrm{K} \alpha$ radiation (Ultima IV, Rigaku Co.). The magnetic properties were measured under magnetic fields of up to $1.5 \mathrm{~T}$ at ambient temperature using a vibrating sample magnetometer (BHV-50, Riken Denshi Co.).

The magnetic resonance of the X-band (8.4-12.4 GHz) was observed at ambient temperature in a magnetic field of $0-800 \mathrm{mT}$ using electron spin resonance (ESR; JES-PX 1050, JEOL). The films were cut into $2 \mathrm{~mm} \times 10 \mathrm{~mm}$ strips together with their $\mathrm{SiO}_{2}$ glass substrates. They were fixed in a Pyrex glass tube using glass wool to maintain the film orientation during the measurements. 


\section{Results and discussion}

\section{Iron nanoparticle-embedded granular thin films prepared by thermal annealing}

Thin films of $\left(\mathrm{Fe}_{1-\mathrm{x}} \mathrm{Al}_{\mathrm{x}}\right) \mathrm{N}$ were prepared by reactive rf-sputter deposition. The as-deposited films crystallized in either a defect rock salt-type $\gamma^{\prime \prime}-\mathrm{FeN}_{0.5 \sim 0.7}(0 \leq \mathrm{x}<0.5)$ or a wurtzite-type $\left(\mathrm{Fe}_{1-\mathrm{x}} \mathrm{Al}_{\mathrm{x}}\right) \mathrm{N}$ solid solution $(0.5 \leq \mathrm{x} \leq 1.0)$, as described in a previous manuscript [12]. After annealing at $600^{\circ} \mathrm{C}$, the rock salt type iron nitride was converted to $\alpha$-Fe with a crystallite size of approximately $40 \mathrm{~nm}$ and $\varepsilon-\mathrm{Fe}_{3} \mathrm{~N}$ impurity in the film with $\mathrm{x}=0$, as shown in Fig. 1 . Highly crystalline $\alpha$-Fe appeared in the annealed film with $x=0.3$. There was a broad and small shoulder around $2 \theta \approx 36^{\circ}$ suggesting a copresence of a small amount of amorphous AlN. The nitrides were relatively stable in the latter wurtzite-type films, but a small amount of $\alpha$-Fe with a crystallite size of approximately $10 \mathrm{~nm}$ appeared at $\mathrm{x}=0.5$ after annealing. Only wurtzite-type $\left(\mathrm{Fe}_{1-\mathrm{x}} \mathrm{Al}_{\mathrm{x}}\right) \mathrm{N}$ was observed at $\mathrm{x}=0.8$, even after annealing. The latter post-annealed films with $(0.5 \leq \mathrm{x} \leq 1.0)$ were electrically insulating, but the former films with $(0 \leq \mathrm{x}<0.5)$ were metallic. Insulating films are required for the observation of magnetic resonance, in order to avoid eddy current loss under electromagnetic wave irradiation. The crystallite size of the $\alpha$-Fe particles decreased at the lower annealing temperature of $450^{\circ} \mathrm{C}$. The annealed $\mathrm{Fe}_{0.5} \mathrm{Al}_{0.5} \mathrm{~N}$ films were soft magnetic, and were similar to the 
samples discussed in our previous manuscript [10]. The film magnetization saturated below $1 \mathrm{~T}$, regardless of the annealing temperature between 450 and $600^{\circ} \mathrm{C}$. The magnetic coercivity was $13 \mathrm{mT}$ in films annealed at $600^{\circ} \mathrm{C}, 12 \mathrm{mT}$ at $500^{\circ} \mathrm{C}$, and $6 \mathrm{mT}$ at $450^{\circ} \mathrm{C}$. These values gradually decreased because of the smaller size of the $\alpha$-Fe particles precipitating in the insulating matrix of wurtzite-type structure with very low crystallinity.

Microwaves were irradiated upon post-annealed $\mathrm{Fe}_{0.5} \mathrm{Al}_{0.5} \mathrm{~N}$ films, which were oriented parallel or perpendicular to the magnetic field. The films showed magnetic resonance, as shown in Fig. 2, similar to the behavior of Ni nanoparticle-embedded polyimide films placed parallel to an applied magnetic field [8]. The resonance intensity was highest for the film annealed at $450^{\circ} \mathrm{C}$, because it contained the smallest magnetic $\alpha$-Fe particles, which were well-distributed in the insulating amorphous matrix. The intensity decreased with increasing annealing temperature, because migration of the magnetic moment was restricted due to the magnetic domains in the larger $\alpha$-Fe particle size. The as-deposited film showed no resonance because it had no ferromagnetic $\alpha$-Fe particles. A weak signal at $150 \mathrm{mT}$ was observed in all measurements because of paramagnetic impurities in the Pyrex sample holder. The resonance intensity was much lower for the annealed $\mathrm{Fe}_{0.2} \mathrm{Al}_{0.8} \mathrm{~N}$ films, because there were fewer precipitated $\alpha-\mathrm{Fe}$ 
particles due to the lower iron content. For this chemical composition of the nitride, the signal intensity decreased with increasing annealing temperature because the number of $\alpha$-Fe particles size smaller than $10 \mathrm{~nm}$ decreased with increasing temperature. 


\section{Iron line drawing by scanning laser heating on $\mathrm{Fe}_{0.7} \mathrm{Al}_{0.3} \mathrm{~N}$ thin film}

Laser light was irradiated on FeN/AlN thin films in a nitrogen atmosphere, which was used to prevent oxidation during the laser heating. A thin AlN underlayer was used to prevent exfoliation of the laser-irradiated films from their silica glass substrates. A focal length of $3 \mathrm{~cm}$ provided a higher line drawing resolution than a $6 \mathrm{~cm}$ focal length, because the laser power was more concentrated in the former case. The drawn line was approximately $200 \mu \mathrm{m}$ wide in the former case, and $500 \mu \mathrm{m}$ in the latter with a laser irradiation power of $2.0 \mathrm{~W}$. The powder XRD showed the film after the irradiation was a poorly crystalline mixture of $\alpha-\mathrm{Fe}$ and $\varepsilon-\mathrm{Fe}_{3} \mathrm{~N}$ although it was a relatively well crystallized $\gamma^{\prime \prime}-\mathrm{FeN}_{0.5 \sim 0.7}$ before the irradiation. The irradiated region was assumed to convert to a mixture of $\alpha-\mathrm{Fe}$ and $\varepsilon-\mathrm{Fe}_{3} \mathrm{~N}$, which contained less nitrogen than the pristine $\gamma^{\prime \prime}-\mathrm{FeN}_{0.5} \sim .7$. Laser writing at $2.5 \mathrm{~W}$ with a 3-cm focal length resulted in a 200 - $\mu \mathrm{m}$-wide $\alpha-\mathrm{Fe}$ line, as shown in Fig. 3, without any $\gamma-\mathrm{Fe}_{3} \mathrm{~N}$ impurity.

Similar laser irradiation was performed on $\mathrm{Fe}_{0.7} \mathrm{Al}_{0.3} \mathrm{~N}$ thin films to draw electrically conductive lines in an insulating matrix. The $\mathrm{Fe}_{0.7} \mathrm{Al}_{0.3} \mathrm{~N}$ thin film was deposited on an AlN underlayer by reactive rf-sputtering using a composite target consisting of distributed $\mathrm{Al}$ chips on an Fe target. It was a poorly crystallized mixture of $\gamma^{\prime \prime}-\mathrm{FeN}_{0.5 \sim 0.7}$ and wurtzite type $\left(\mathrm{Fe}_{1-\mathrm{x}} \mathrm{Al}_{\mathrm{x}}\right) \mathrm{N}(0.6 \leq \mathrm{x} \leq 1.0)$ as depicted in Fig. 4(a) [12]. The 
sputtering was performed in a nitrogen atmosphere at $5.5 \mathrm{~Pa}$ with $100 \mathrm{~W}$ of rf power for $2 \mathrm{~h}$, in a process similar to that described in the previous section. The laser was irradiated upon the as-deposited thin film at a power of $2.5 \mathrm{~W}$ using a 3-cm focal length. Lines $200 \mu \mathrm{m}$ wide were drawn by scanning the laser at $1.0 \mathrm{~mm} / \mathrm{s}$, as shown in Fig. 5 . The irradiated thin film was a mixture of $\alpha-\mathrm{Fe}, \gamma-\mathrm{Fe}_{4} \mathrm{~N}$, and pristine $\mathrm{Fe}_{0.7} \mathrm{Al}_{0.3} \mathrm{~N}$, as shown in Fig. 4(b). XRD results suggested that the lines were mostly $\alpha$-Fe, with some $\gamma-\mathrm{Fe}_{4} \mathrm{~N}$ impurity. Their electrical resistivity measured in two point contact was $300 \Omega \mathrm{cm}$ in the line part, while the matrix resistivity was $2 \mathrm{k} \Omega \mathrm{cm}$. The film thickness shrank from $0.6 \mu \mathrm{m}$ to $0.3 \mu \mathrm{m}$ by the irradiation. The present $\alpha$-Fe lines were much wider than the reported resolution available by thermal patterning [2]. The use of nitrides sensitive to temperature, such as $\mathrm{Cu}_{3} \mathrm{~N}$ and $\mathrm{Zn}_{3} \mathrm{~N}_{2}$, should improve the resolution in lower applied laser irradiation power.

In conclusion, $\alpha$-Fe nanoparticle-embedded granular thin films were prepared by the post-annealing of reactive rf-sputter-deposited $\mathrm{Fe}_{0.5} \mathrm{Al}_{0.5} \mathrm{~N}$ thin films. The films showed magnetic resonance in the microwave region with the highest intensity occurring in films annealed at $450^{\circ} \mathrm{C}$. The resonance indicated a negative permeability value. Metallic Fe lines $200 \mu \mathrm{m}$ wide were drawn to obtain a negative permittivity in an 
$\mathrm{Fe}_{0.7} \mathrm{Al}_{0.3} \mathrm{~N}$ thin film by laser direct writing in a nitrogen atmosphere using an AlN underlayer. A negative refractive index value could be achieved by optimizing the negative values of both permeability and permittivity obtained by thermal and scanning-laser annealing of Fe-Al nitride thin films.

\section{Acknowledgement}

This research was supported in part by a Grant-in-Aid for Exploratory Research \#20655045, JSPS KAKENHI. 


\section{References}

[1] R. H. French and H. V. Tran, Annu. Rev. Mater. Res., 39, 93-126 (2009).

[2] M. Kuwahara, C. Mihalcea, N. Atoda, J. Tominaga, H. Fuji and T. Kikukawa, Microelectronic Engineering, 61-62, 415-421 (2002).

[3] J. B. Pendry and D. R. Smith, Scientific American, 295, 60-67 (2006).

[4] N. Engheta and R. W. Ziolkowski Eds.; Metamaterials, Physics and Engineering Explorations; IEEE Press: Piscataway, NJ, 2006.

[5] D. R. Smith, W. J. Padilla, D. C. Vier, S. C. Nemat-Nasser and S. Schultz, Phys. Rev. Lett., 84, 4184-4187 (2000).

[6] T. J. Yen, W. J. Padilla, N. Fang, D. C. Vier, D. R. Smith, J. B. Pendry, D. N. Basov and X. Zhang, Science, 303, 1494-1496 (2004).

[7] S. T. Chui and L. Hu, Phys. Rev. B, 65, 144407-1/144407-6 (2002).

[8] C. Mitsumata and S. Tomita, Appl. Phys. Lett., 91, 223104-1/3 (2007).

[9] B. Eck, R. Dronskowski, M. Takahashi and S. Kikkawa, J. Mater. Chem, 9, 1527-1537 (1999) .

[10] Y. Kawaai, A. Yamada, T. Takeda and S. Kikkawa, Jpn. J. Appl. Phys. 43, 5671-5672 (2004).

[11] K. Sakon, Y. Hirokawa, Y. Masubuchi and S. Kikkawa, Mater. Sci. Forum. 631-632, 
327-331 (2010).

[12] S. Kikkawa, M. Fujiki, M. Takahashi and F. Kanamaru, J. Jpn. Soc. Powder and Powder Metall., 44 (7), 674-677 (1997).

[13] H. Nakagawa, S. Nasu, H. Fujii, M. Takahashi and F. Kanamaru, Hyperfine Interactions, 69, 455-458 (1991).

[14] G. A. Jeffrey, G. S. Parry and R. L. Mozzi, J. Chem. Phys., 25, 1024-1031 (1956).

[15] H. Jacobs, D. Rechenbach and U. Zachwieja, J. Alloys \& Compd., 227, 10-17 (1995).

[16] M. E. Straumanis and D. C. Kim, Z Metallkunde, 60, 272-277 (1969). 


\section{Figure captions}

Fig. $1 \mathrm{X}$-ray diffraction patterns of $\mathrm{Fe}_{1-\mathrm{x}} \mathrm{Al}_{\mathrm{x}} \mathrm{N}$ thin films post-annealed at $600^{\circ} \mathrm{C}$, (a) $\mathrm{x}=$ 0 , (b) $x=0.3$, (c) $x=0.5$, and (d) $x=0.8$. Diffraction lines are marked with stars for $\alpha$-Fe, and open and filled diamonds for $\varepsilon-\mathrm{Fe}_{3} \mathrm{~N}$, and wurtzite-type $\mathrm{Fe}_{1-\mathrm{x}} \mathrm{Al}_{\mathrm{x}} \mathrm{N}(0.5 \leq \mathrm{x} \leq$ $1.0)$, respectively.

Fig. 2 Microwave resonance of as-deposited and annealed $\mathrm{Al}_{0.5} \mathrm{Fe}_{0.5} \mathrm{~N}$ thin films at several temperatures.

Fig. 3 Optical microscopic observations of laser lines drawn on an FeN thin film deposited on an AlN underlayer.

Fig. 4 X-ray diffraction patterns of $\mathrm{Fe}_{0.7} \mathrm{Al}_{0.3} \mathrm{~N} / \mathrm{AlN}$ thin films (a) as-deposited, and (b) laser line drawn. Theoretical patterns were also shown using literature values for defect rock salt type $\gamma^{\prime \prime}-\mathrm{FeN}_{0.5 \sim 0.7}$ [13], AlN [14], $\gamma-\mathrm{Fe}_{4} \mathrm{~N}$ [15] and $\alpha-\mathrm{Fe}$ [16]. The as-deposited film poorly crystallized as a mixture of $\gamma^{\prime \prime}-\mathrm{FeN}_{0.5 \sim 0.7}$ and wurtzite type $\left(\mathrm{Fe}_{1-\mathrm{x}} \mathrm{Al}_{\mathrm{x}}\right) \mathrm{N}(0.6 \leq$ $\mathrm{x} \leq 1.0)$.

Fig. 5 Optical microscopic observation of laser lines drawn on a $\mathrm{Fe}_{0.7} \mathrm{Al}_{0.3} \mathrm{~N}$ thin film deposited on an AlN underlayer. 


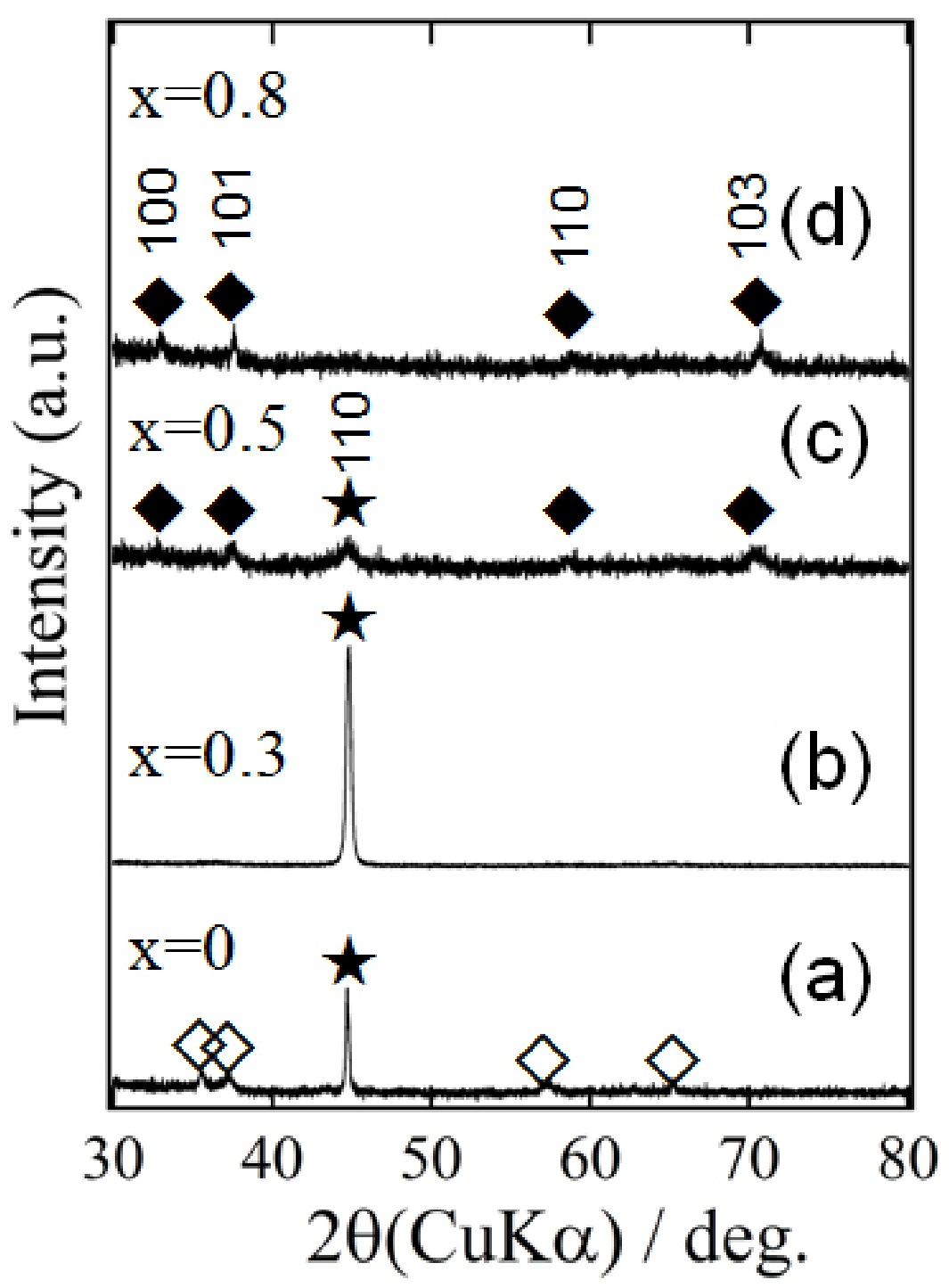

Fig. $1 \mathrm{X}$-ray diffraction patterns of $\mathrm{Fe}_{1-\mathrm{x}} \mathrm{Al}_{\mathrm{x}} \mathrm{N}$ thin films post-annealed at $600^{\circ} \mathrm{C}$, (a) $\mathrm{x}=$ 0 , (b) $x=0.3$, (c) $x=0.5$, and (d) $x=0.8$. Diffraction lines are marked with stars for $\alpha$-Fe, and open and filled diamonds for $\varepsilon-\mathrm{Fe}_{3} \mathrm{~N}$, and wurtzite-type $\mathrm{Fe}_{1-\mathrm{x}} \mathrm{Al}_{\mathrm{x}} \mathrm{N}(0.5 \leq \mathrm{x} \leq$ $1.0)$, respectively. 


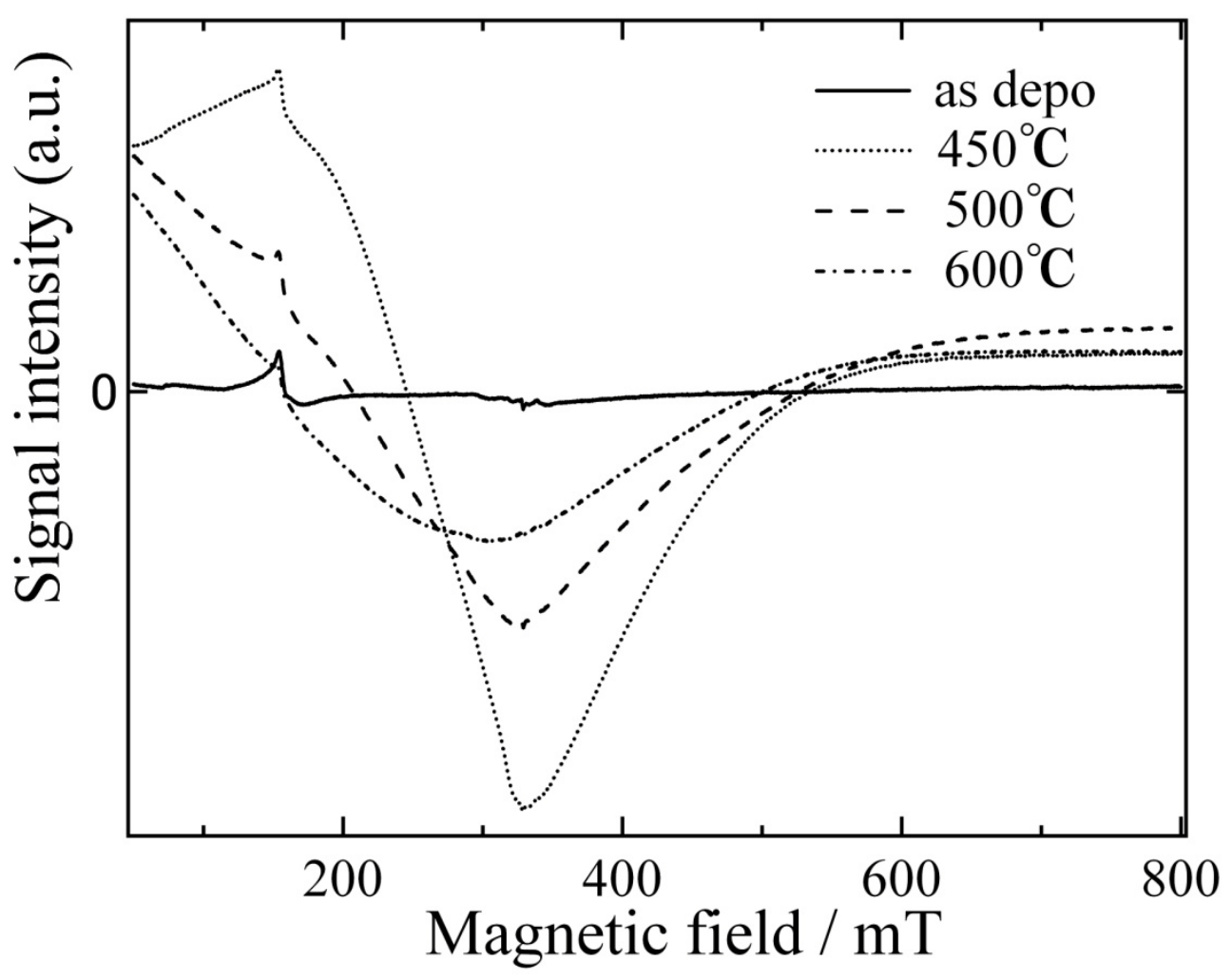

Fig. 2 Microwave resonance of as-deposited and annealed $\mathrm{Al}_{0.5} \mathrm{Fe}_{0.5} \mathrm{~N}$ thin films at several temperatures. 


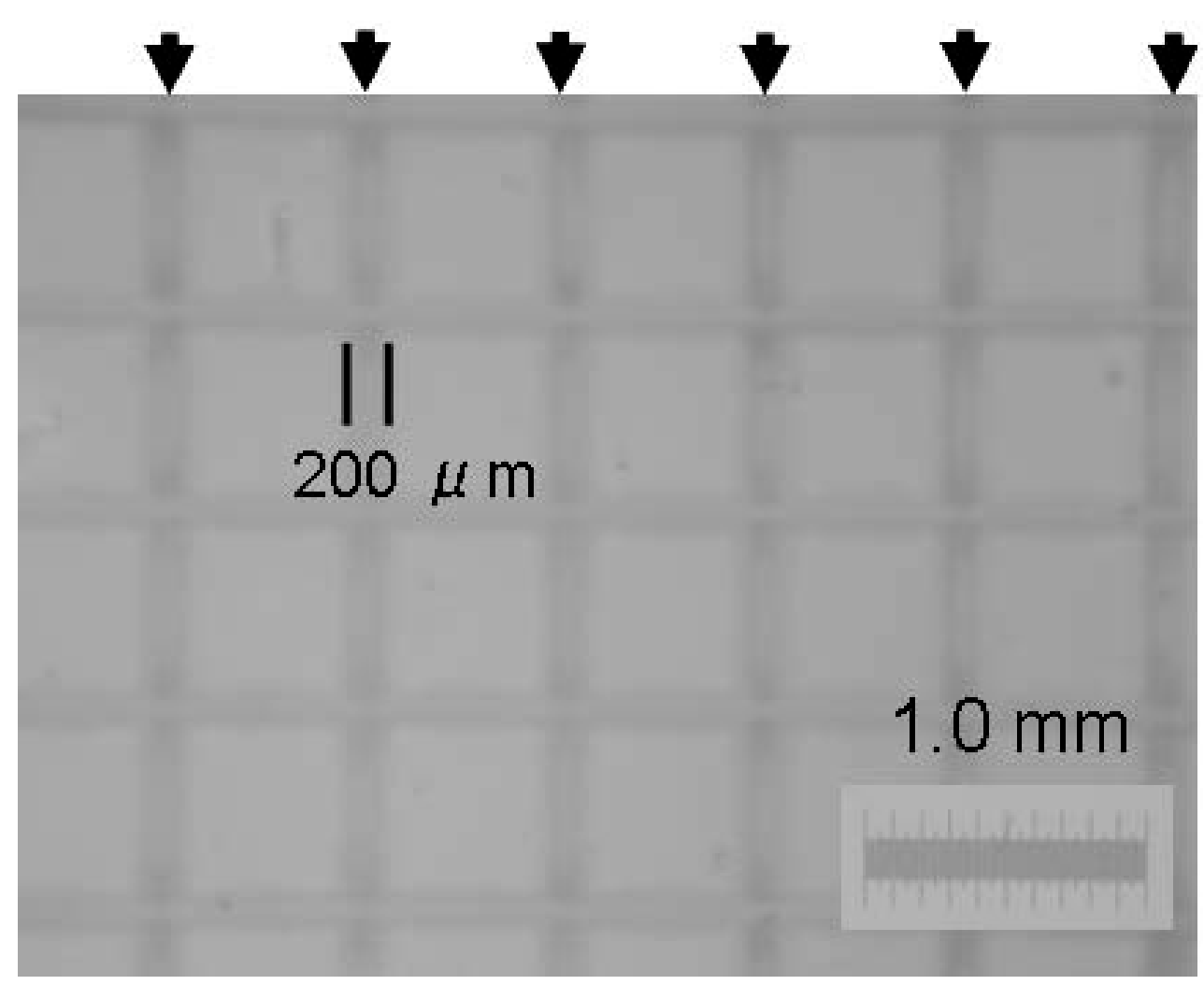

Fig. 3 Optical microscopic observations of laser lines drawn on an FeN thin film deposited on an AlN underlayer. 


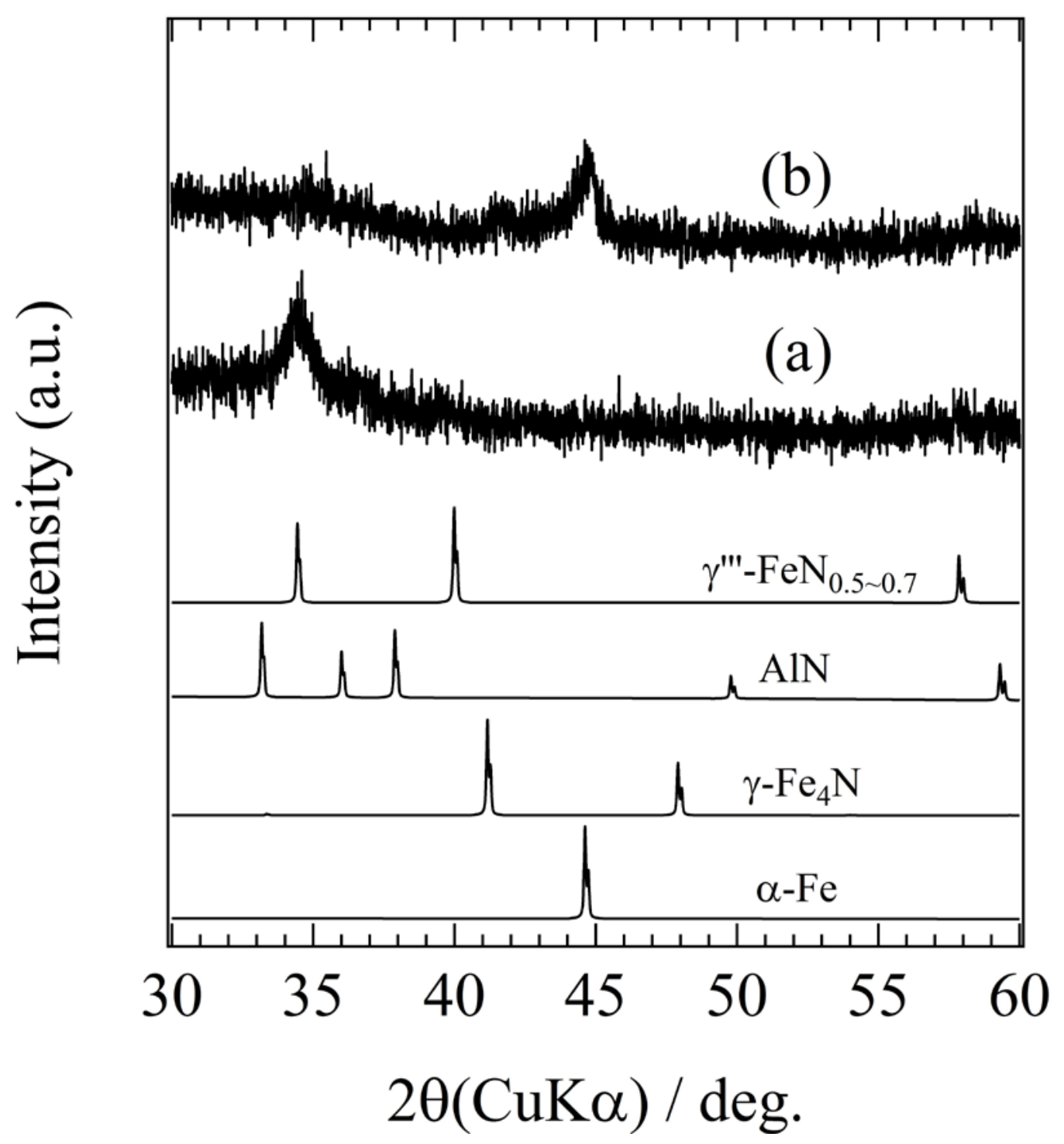

Fig. 4 X-ray diffraction patterns of $\mathrm{Fe}_{0.7} \mathrm{Al}_{0.3} \mathrm{~N} / \mathrm{AlN}$ thin films (a) as-deposited, and (b) laser line drawn. Theoretical patterns were also shown using literature values for defect rock salt type $\gamma^{\prime \prime}-\mathrm{FeN}_{0.5} 0.7$ [13], AlN [14], $\gamma$-Fe ${ }_{4} \mathrm{~N}$ [15] and $\alpha$-Fe [16]. The as-deposited film poorly crystallized as a mixture of $\gamma^{\prime \prime}-\mathrm{FeN}_{0.5 \sim 0.7}$ and wurtzite type $\left(\mathrm{Fe}_{1-\mathrm{x}} \mathrm{Al}_{\mathrm{x}}\right) \mathrm{N}(0.6 \leq$ $\mathrm{x} \leq 1.0)$. 


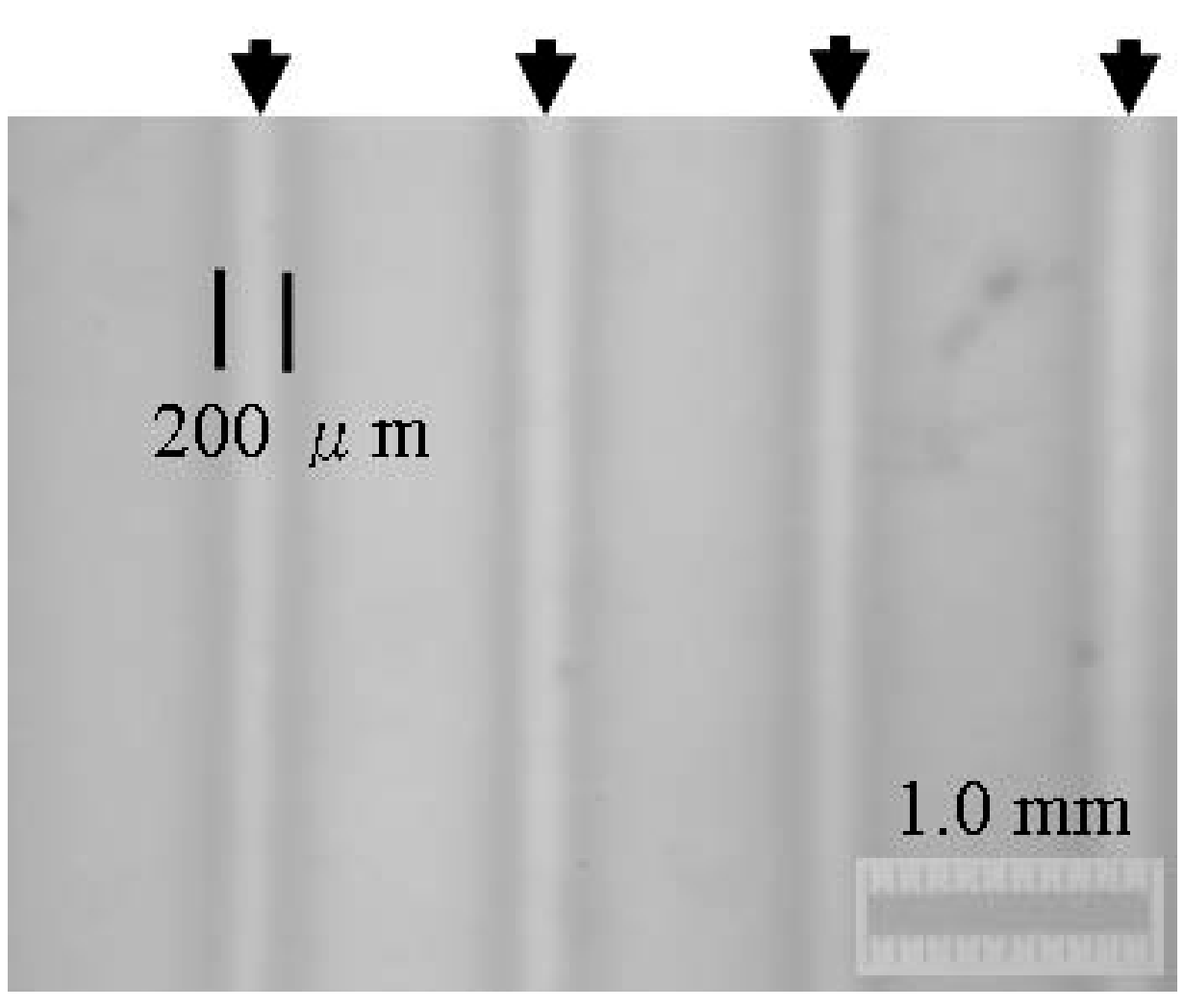

Fig. 5 Optical microscopic observation of laser lines drawn on a $\mathrm{Fe}_{0.7} \mathrm{Al}_{0.3} \mathrm{~N}$ thin film deposited on an AlN underlayer. 